\title{
Validated Eco-Friendly Chromatographic Methods for Simultaneous Determination of Sacubitril and Valsartan in Spiked Human Plasma and in Pharmaceutical Formulation
}

\author{
Amal Mahmoud Abou Al Alamein \\ Analytical Chemistry Department, Faculty of Pharmacy, Cairo University, 11562 Cairo, Egypt.
}

\begin{tabular}{|c|c|}
\hline ARTICLE INFO & ABSTRACT \\
\hline $\begin{array}{l}\text { Article history: } \\
\text { Received on: } 21 / 10 / 2017 \\
\text { Accepted on: } 30 / 12 / 2017 \\
\text { Available online: } 27 / 02 / 2018\end{array}$ & $\begin{array}{l}\text { Two eco-friendly chromatographic approaches are developed for simultaneous quantification of Sacubitril (SAC) } \\
\text { and Valsartan (VAL) in combined formulation. The first method depended on isocratic HPLC separation of the } \\
\text { two medications on the reversed phase InertsiL ODS- } 3 \text { column " } \mathrm{C}_{18}(5 \mu \mathrm{m}, 150 \mathrm{~mm} \times 4.0 \mathrm{~mm} \text {, i.d.)" at ambient } \\
\text { temperature utilizing a green mobile phase consisting of methanol: ethanol: water }(40: 30: 30 \text {, by volumes) }+0.1 \% \\
\text { triethyl amine, pH } 3.5 \text { with UV detection at } 267 \mathrm{~nm} \text {. Linearity was attained for both drugs at concentration ranges }\end{array}$ \\
\hline $\begin{array}{l}\text { Key words: } \\
\text { Sacubitril, Valsartan, HPLC, } \\
\text { HPTLC, Green chemistry }\end{array}$ & 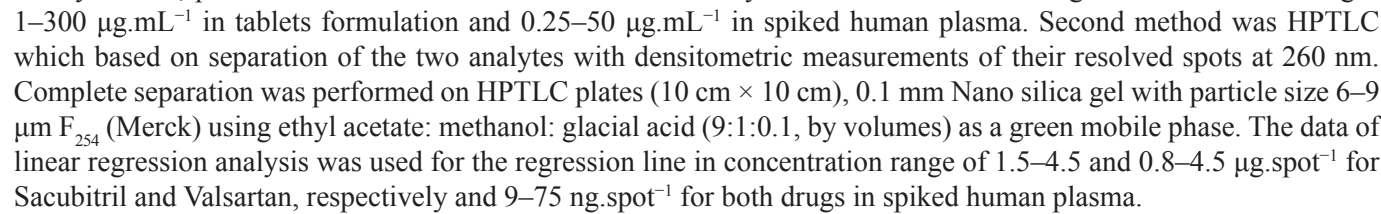 \\
\hline
\end{tabular}

\section{INTRODUCTION}

HPLC and HPTLC are considered routine analytical separation techniques that are applied for qualitative and quantitative purposes but unfortunately, majority of these conventional techniques either consume or produce dangerous organic solvents that harmfully affect humans and the surrounding environment. So, the development of greener methods became favorable which is accomplished by developing analytical methods in a safe way that decreases or disposes of unwanted toxic substances that are utilized or produced by the method to be safer to nature (Armenta et al., 2008; Koel and Kaljurand, 2006). However, the greater part of the applied chromatographic methods doesn't concern about the green viewpoints, some modern analytical methods (Namieśnik, 2001) presented examples of the application of an ecofriendly approach that was developed for separation of fingerprinting complex matrices (Funari, 2014).

${ }^{*}$ Corresponding Author

Amal Mahmoud Abou Al Alamein, Analytical Chemistry Department, Faculty of Pharmacy, Cairo University.E-mail: amal_alamein@yahoo. com,amal.alamein@pharma.cu.ecu.edu.eg
Sacubitril (SAC) is chemically " $3-\{[(2 \mathrm{~S}, 4 \mathrm{R})-1$ $\{[1,1$ '-biphenyl]-4-yl $\}$-5-ethoxy-4-methyl-5-oxopentan-2-yl] carbamoyl\} propanoic acid" (Figure 1). Sacubitril is an antihypertensive that belongs to the class of neprilysin inhibitor, (McMurray, 2014) Valsartan is chemically "2S-3-methyl-2[N-(\{4-[2-(2H-1,2,3,4-tetrazol-5-yl)phenyl]phenyl $\}$ methyl) pentanamido] butanoic acid" (Figure 1). Valsartan (VAL) is a potent anti-hypertensive drug that is classified as an Angiotensin II receptor blocker that blocks the effect of angiotensin II in the rennin-angiotensin system and furthermore delaying the progress of chronic heart failure (Thurmann, 2000). The use of novel drug combination of sacubitril and valsartan was clinically approved for the treatment of heart failure and minimizing the consequences of cardiovascular and renal disorders (Lawrence, 2014).

In July 2015 "US Food and Drug Administration (FDA)" approved Entresto tablets as a combined formulation of sacubitril and valsartan for the treatment of heart failure. By administration of ENTRESTO, the neprilysin is inhibited by the active metabolite (LBQ657) of the prodrug sacubitril, and the angiotensin II type-1 
receptor is blocked by valsartan. (FDA, 2015.). Following oral administration, the maximum plasma concentrations are reached in 0.5 hours, 2.5 hours, and 2 hours for sacubitril, LBQ657, and

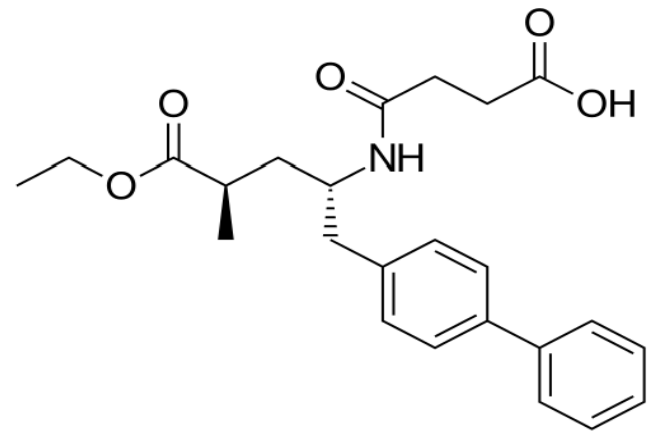

Sacubitril valsartan, in order with a mean elimination half-life $(\mathrm{T} 1 / 2)$ of about 1.4 hours, 11.5 hours, and 9.9 hours, respectively (Kobalava et al., 2016).

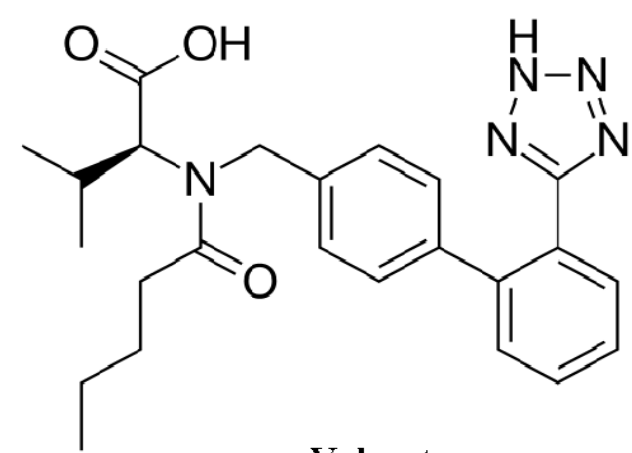

Valsartan.

Fig. 1: Chemical structures of sacubitril and valsartan.

From the literature survey, it was found that several methods are reported on determination of Valsartan either individually (Hakan et al., 2016; Macek et al., 2006; Koseki et al., 2007) or combined with other drugs (Siddhartha et al., 2014; Gandla et al., 2014; Jothiswari et al., 2010; Hao Li et al., 2007; Eric et al., 1996). However, few HPLC methods (Kena et al., 2016; Muqhtar et al., 2017; Swathi and Parthiban, 2017; Naazneen and Sridevi, 2017; Madana and Sridhar, 2017), LC mass (Raja Haranadha and Gowri, 2016) and spectrofluorimetric method (Ragab et al., 2017) have been reported for simultaneous determination of Sacubitril and Valsartan in combination. Till date literature review revealed that no TLC method has been reported for the simultaneous analysis of the cited drugs. So, this work aimed to the development of accurate, precise and selective green chromatographic methods for the analysis of Sacubitril and Valsartan in synthetic mixture, pharmaceutical formulation and in human plasma.

\section{EXPERIMENTAL}

\section{Instrumentation}

Shimadzu HPLC Chromatograph, equipped with a quaternary pump LC 10AD VP, variable wavelength detector (Model SPD-10AVB, Schimadzu-Kyoto-Japan, injector with $20 \mu \mathrm{l}$ loop volume, and auto sampler injector model SL-20A, Schimadzu-Kyoto-Japan. Software was applied for data collecting and processing.

Camag TLC scanner 3 "Camag, Muttenz, Switzerland" operated on Wincat "software version 3.15" in fluorescence mode at $366 \mathrm{~nm}$ using mercury lamp and applying optical filter k 400, Linomat 3 auto sampler (Camag, Muttenz, Switzerland); HPTLC plates $(10 \mathrm{~cm} \times 10 \mathrm{~cm}), 0.1 \mathrm{~mm}$ nano silica gel with particle size 6-9 $\mu \mathrm{m} \mathrm{F}_{254}$ (Merck).

\section{Standards, samples, and chemicals}

Pharmaceutical grade of Sacubitril and Valsartan standards were received as gift samples from "National Organization for Drug Control and Research" (NODCAR)Egypt, certified to contain 100.53 and $99.85 \%$ for SAC and VAL, respectively according to a reported HPLC method (Kena et al., 2016). Entresto ${ }^{\mathrm{TM}}$ tablets, Batch No. T0001 containing $49 \mathrm{mg}$ Sacubitril and $51 \mathrm{mg}$ Valsartan per each tablet were manufactured by "Novartis Pharma Stein AG, Switzerland for Novartis Pharma AG, Basle, Switzerland" and purchased from Saudi Arabian market. Ethanol and methanol were of HPLC grade (E. Merck, Darmstadt, Germany). Ethyl acetate, methanol and glacial acid (E. Merck, Darmstadt, Germany). Double distilled water was used, and the other chemicals were analytical grade.

\section{Chromatographic conditions}

For the HPLC method: best resolution and complete base line separation were achieved using InertsiL ODS-3 column $\mathrm{C}_{18}(5$ $\mu \mathrm{m}, 150 \mathrm{~mm} \times 4.0 \mathrm{~mm}$, i.d.) at ambient temperature with a green mobile phase composed of methanol: ethanol: water (40:30:30, by volumes $)+0.1 \%$ triethyl amine, $\mathrm{pH}$ is finally adjusted to 3.5 with Ortho phosphoric acid. It was filtered through $0.45 \mu$ membrane filter, degassed and pumped at $0.8 \mathrm{ml} / \mathrm{min}$. The injection volumes of samples were $20 \mu \mathrm{l}$. The eluents were detected at $267 \mathrm{~nm}$.

The HPTLC method was performed on HPTLC plates $(10 \mathrm{~cm} \times 10 \mathrm{~cm}), 0.1 \mathrm{~mm}$ Nano silica gel with particle size $6-9$ $\mu \mathrm{m}, \mathrm{F}_{254}$ (Merck); the samples were applied as spots utilizing an automatic CAMAG microliter syringe "bandwidth: $4 \mathrm{~mm}$; spacing: $13.8 \mathrm{~mm} ; 10 \mathrm{~mm}$ from the bottom edge of the plate". The plates were ascendingly developed in a chromatographic tank, previously saturated with the suggested mobile phase; ethyl acetate: methanol: glacial acid (9:1:0.1, by volumes) for $1 \mathrm{~h}$ at room temperature. After the plates had been developed, they were air dried and scanned at $260 \mathrm{~nm}$ for both drugs on a "Camag TLC scanner 3" operated in the absorbance mode, using a deuterium lamp as a source of radiation.

\section{Standard solutions}

Standard stock solutions of $1000 \mu \mathrm{g} \cdot \mathrm{mL}^{-1} \mathrm{SAC}$ and VAL were prepared separately by dissolving the specified weight in methanol. For the HPLC method, different working standard solutions containing 1-300 $\mu \mathrm{g} \cdot \mathrm{mL}^{-1}$ of SAC and VAL were prepared by suitable dilutions of their respective stock solutions using the selected mobile phase as a solvent. 


\section{Construction of calibration curves}

For the RP-HPLC method, Aliquots of $20 \mu \mathrm{L}$ from SAC and VAL working standard solutions were injected in triplicate and analyzed for each solution sample. For equilibrium, pre-washing and conditioning of the stationary phase, about of $50-60 \mathrm{~mL}$ of the mobile phase has been passed before the analysis was performed. The relative peak area ratios "drug/external standard", were calculated using $50 \mathrm{mg} / \mathrm{mL}$ of SAC or VAL as external standards for their respective samples, and then plotted against the corresponding drug concentrations to construct the calibration graphs.

For HP TLC-densitometry, aliquot volumes equal to $1.5-4.5 \mu \mathrm{g} / \mathrm{spot}$ of SAC and $0.8-4.5 \mu \mathrm{g} / \mathrm{spot}$ of VAL were transferred from their standard solutions $\left(1000 \mu \mathrm{g} \cdot \mathrm{mL}^{-1}\right.$ in methanol) and applied as spots in triplicate to TLC plates using a Camag Linomat IV applicator. The spots were analyzed and scanned using the specified chromatographic conditions. The calibration curves were plotted by relating the integrated peak areas to the corresponding concentrations of the cited drugs, as $\mu \mathrm{g} / \mathrm{spot}$.

\section{Plasma sample preparation}

Aliquot of $1 \mathrm{~mL}$ human plasma was pipetted into two series of 6-mL screw-capped glass tubes. The samples were spiked with different microliters of SAC and VAL stock standard solutions separately and extracted with $1 \mathrm{ml}$ methanol and 1.0 $\mathrm{mL}$ acetonitrile by shaking for $20 \mathrm{~min}$ (Koçyiğit-Kaymakçoğlu, 2006). After $10 \mathrm{~min}$ of centrifugation at $5000 \mathrm{rpm}$, the organic extracts were quantitatively transferred to clean tubes and evaporated at room temperature under a stream of nitrogen. Then the samples were reconstituted using either $1 \mathrm{~mL}$ of the suggested mobile phase for the HPLC method or $1 \mathrm{~mL}$ methanol for TLC method. The prepared samples were subjected to suggested chromatographic analysis using the optimized chromatographic conditions.

\section{Analysis of laboratory prepared binary mixtures}

Aliquots of "SAC and VAL" standard solutions were mixed to prepare mixtures containing different ratios of the drugs. The prepared samples were analyzed according to the proposed chromatographic methods and the concentrations of the cited drugs were then calculated from their regression equations.

\section{Analysis of tablet formulation}

Twenty Entresto ${ }^{\mathrm{TM}}$ tablets were weighed accurately, finely powdered, and then an accurate weight of powder equivalent to "49 $\mathrm{mg}$ SAC and $51 \mathrm{mg}$ VAL" was transferred into a100-mL beaker. The powder was extracted with $\sim 50 \mathrm{~mL}$ methanol via continuous magnetic stirring for $\sim 10 \mathrm{~min}$, then filtering of the solution was done into a $100-\mathrm{mL}$ measuring flask, and the volume was finally adjusted using the same solvent. Any further dilutions of the prepared solutions were made using either methanol for TLC method or the mobile phase for HPLC.

The developed methods were successfully applied for the quantitative analysis of SAC and VAL in their pharmaceutical formulation using the optimized procedures mentioned before, and the analytes concentrations were accurately calculated from their corresponding regression equations.

\section{RESULTS AND DISCUSSION}

\section{Method development}

The presented work is concerned with the simultaneous determination of SAC and VAL using two different chromatographic techniques. The aim of suggested work was to develop greener or more benign methods which could replace other conventional dangerous ones for the routine analysis of the studied drugs taking into consideration two main aspects based on the safety of the selected solvents and the minimization of the resulted hazardous waste (Elzanfaly et al., 2015). To select a solvent properly from an eco-friendly viewpoint, the hazardous solvents should be substituted by others that have better "environmental, health, and safety (EHS)" properties.

Ethanol being less toxic solvent derived from natural renewable sources could be favorably selected as a green solvent. Therefore, according to "EHS" criteria the solvents selected in the proposed methods namely; ethanol, methanol, ethyl acetate and water are considered environmentally favorable (Alfonsi et al., 2008). So, the proposed methods presented in this work have more privileges over the reported chromatographic ones of the studied drug mixtures which utilized acetonitrile that is described as hazardous non-biodegradable solvent.

In the developed HPLC method, complete base line separation, good resolution and symmetrical peaks for SAC \& VAL were attained by using a green mobile phase consisting of methanol + ethanol + water (40:30:30, by volumes) $+0.1 \%$ triethyl amine, $\mathrm{pH}$ is finally adjusted to 3.5 with o-phosphoric acid. The short separation time $(5 \mathrm{~min})$ and fast flow rate $(0.8 \mathrm{~mL} / \mathrm{min})$ led to minimize the produced waste to a range of $2.0-5.0 \mathrm{~mL} / \mathrm{run}$ which is considered an important measure from the greener view point. This shows that the developed method saves run time, consumed solvents and minimizes the toxic waste.

This method allowed the simultaneous quantitation of the two drugs in the range of $1-300 \mu \mathrm{g} \cdot \mathrm{mL}^{-1}$ with UV detection at $267 \mathrm{~nm}$ (Figure $2 \mathrm{~A}$ ), as direct spectrophotometric determination was hindered because of the severe spectral overlap between the analyzed drugs. In addition, the proposed HPLC method shows higher sensitivity over the previously reported HPLC ones (Kena et al., 2016; Muqhtar et al., 2017; Swathi and Parthiban, 2017; Naazneen and Sridevi, 2017; Madana and Sridhar, 2017) in terms of lower linearity range (1-300 $\left.\mu \mathrm{g} \cdot \mathrm{mL}^{-1}\right)$ in pure samples and 0.25 $50 \mu \mathrm{g} \cdot \mathrm{mL}^{-1}$ in human plasma and lower LOD and LOQ values in nanogram level as listed in Table 1 . System suitability parameters were tested and statistically analyzed for HPLC method and indicated a good resolution of the two components.

The Second method is HPTLC-densitometric procedure; different mobile phases were tried, where good separation of SAC and VAL was obtained using ethyl acetate: methanol: glacial acid (9:1:0.1, by volumes) as a green mobile phase. The average $\mathrm{Rf}$ values were found to be 0.61 for VAL and 0.84 for SAC as in Figure 3.

TLC-Densitometric technique allows selective determination of SAC and VAL in the range of 1.5-4.5 and 0.8$4.5 \mu \mathrm{g} . \mathrm{spot}^{-1}$, respectively and 9-75 ng. spot $^{-1}$ for both drugs in spiked human plasma. The regression equations were computed and results are summarized in Table 1. 
Table 1: Regression and validation parameters of determination of VAL and SAC pure samples by the proposed chromatographic methods.

\begin{tabular}{|c|c|c|c|c|c|c|c|c|}
\hline \multirow{3}{*}{$\begin{array}{l}\text { Parameters } \\
\text { Sample }\end{array}$} & \multicolumn{4}{|c|}{ HPLC method } & \multicolumn{4}{|c|}{ Densitometric HPTLC method } \\
\hline & \multicolumn{2}{|c|}{ SAC } & \multicolumn{2}{|c|}{ VAL } & \multicolumn{2}{|c|}{ SAC } & \multicolumn{2}{|c|}{ VAL } \\
\hline & Pure sample & Human plasma & Pure sample & Human plasma & Pure sample & Human plasma & Pure sample & Human plasma \\
\hline Linearity & $1-300 \mu \mathrm{g} \cdot \mathrm{mL}^{-1}$ & $0.25-50 \mu \mathrm{g} \cdot \mathrm{mL}^{-1}$ & $1-300 \mu \mathrm{g} \cdot \mathrm{mL}^{-1}$ & $0.25-50 \mu \mathrm{g} \cdot \mathrm{mL}^{-1}$ & 1.5-4.5 $\mu \mathrm{g}$. spot $^{-1}$ & $9-75$ ng.spot ${ }^{-1}$ & $0.8-4.5 \mu \mathrm{g} . \mathrm{spot}^{-1}$ & $9-75$ ng.spot ${ }^{-1}$ \\
\hline Slope \pm RSD $\%$ & $1.1112 \pm 0.002$ & $1.2475 \pm 0.156$ & $1.9662 \pm 0.113$ & $0.7412 \pm 0.125$ & $0.5293 \pm 0.245$ & $0.0836 \pm 0.023$ & $0.4078 \pm 0.134$ & $0.1099 \pm 0.025$ \\
\hline Intercept \pm RSD \% & $2.3074 \pm 0.213$ & $0.2049 \pm 0.157$ & $4.0579 \pm 0.102$ & $0.0621 \pm 0.022$ & $0.8522 \pm 0.125$ & $0.661 \pm 0.205$ & $2.366 \pm 0.105$ & $0.209 \pm 0.118$ \\
\hline $\begin{array}{l}\text { Correlation coefficient } \\
\text { (r) }\end{array}$ & 0.9999 & 0.9999 & 0.9999 & 0.9999 & 0.9996 & 0.9992 & 0.9997 & 0.9996 \\
\hline $\begin{array}{l}\text { Mean recovery \% } \\
\pm \text { SD }\end{array}$ & $100.15 \pm 0.420$ & $100.56 \pm 0.558$ & $100.12 \pm 0.535$ & $99.98 \pm 0.677$ & $99.95 \pm 0.645$ & $99.89 \pm 0.534$ & $100.05 \pm 0.902$ & $100.24 \pm 0.702$ \\
\hline LOD & $308.6 \mathrm{ng} \cdot \mathrm{mL}^{-1}$ & 74.9 ng. $\mathrm{mL}^{-1}$ & $243 \mathrm{ng} \cdot \mathrm{mL}^{-1}$ & $29 \mathrm{ng} \cdot \mathrm{mL}^{-1}$ & 262 ng.spot ${ }^{-1}$ & 2.02 ng.spot ${ }^{-1}$ & 202 ng.spot ${ }^{-1}$ & 2.45 ng.spot ${ }^{-1}$ \\
\hline LOQ & 935 ng. $\mathrm{mL}^{-1}$ & $226.8 \mathrm{ng} \cdot \mathrm{mL}^{-1}$ & 737 ng. $\mathrm{mL}^{-1}$ & 88.2 ng. $\mathrm{mL}^{-1}$ & 794 ng.spot ${ }^{-1}$ & 6.13 ng.spot ${ }^{-1}$ & 613 ng.spot ${ }^{-1}$ & 7.42 ng.spot ${ }^{-1}$ \\
\hline \multicolumn{9}{|l|}{ Precision (RSD\%) } \\
\hline Repeatability (a) & $\begin{array}{c}0.325-0.832- \\
0.523\end{array}$ & $\begin{array}{c}0.475-0.345- \\
0.678\end{array}$ & $\begin{array}{l}0.425-0.234- \\
0.255\end{array}$ & $\begin{array}{c}0.895-0.566- \\
0.356\end{array}$ & $\begin{array}{l}0.538-0.323- \\
0.458\end{array}$ & $\begin{array}{c}0.718-0.745- \\
0.678\end{array}$ & $\begin{array}{c}0.568-0.897- \\
0.580\end{array}$ & $\begin{array}{l}0.722-0.770- \\
0.554\end{array}$ \\
\hline Reproduci0bility (b) & $\begin{array}{c}0.797-0.564- \\
0.345\end{array}$ & $\begin{array}{c}1.015-0.567- \\
.0 .789-\end{array}$ & $\begin{array}{c}0.402 .0325- \\
0.457\end{array}$ & $\begin{array}{c}0.872-.0 .765- \\
0.467\end{array}$ & $\begin{array}{c}0.466-0.445- \\
0.356\end{array}$ & $\begin{array}{c}0.875-0.338- \\
0.558\end{array}$ & $\begin{array}{l}0.558-0.989- \\
0.996\end{array}$ & $\begin{array}{c}1.032-0.897- \\
0.655\end{array}$ \\
\hline Robustness & $100.25 \pm 1.20$ & $99.85 \pm 1.05$ & $99.95 \pm 0.68$ & $100.35 \pm 0.97$ & $99.95 \pm 0.65$ & $99.78 \pm 0.94$ & $100.45 \pm 0.88$ & $99.88 \pm 1.08$ \\
\hline
\end{tabular}

(a) The intra-day $(n=9)$, Average of three different concentrations repeated three times within day;

(b) The inter-day $(n=9)$, Average of three different concentrations repeated three times in three successive days.
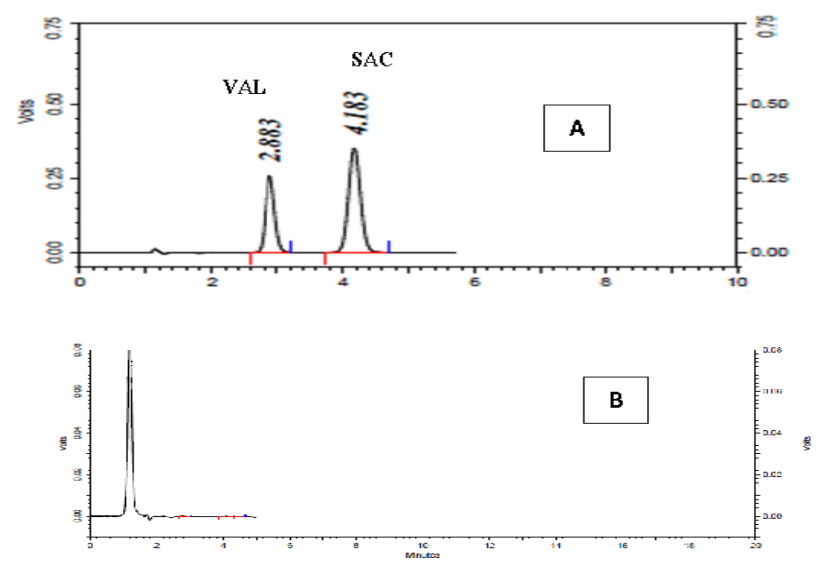
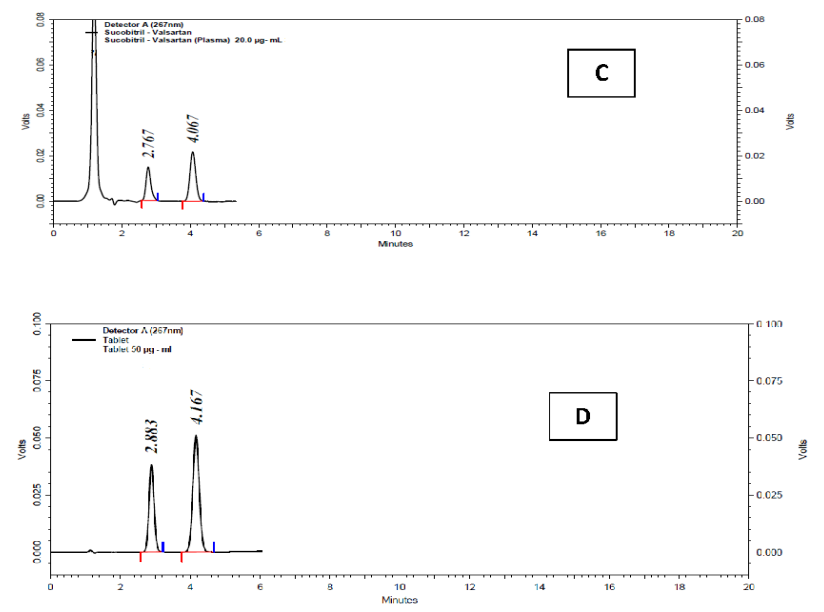

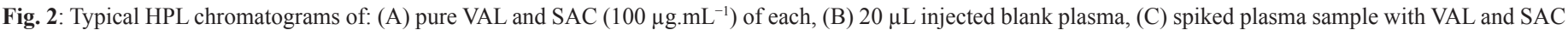
$\left(20 \mu \mathrm{g} \cdot \mathrm{mL}^{-1}\right)$ of each, (D) tablet sample $\left(50 \mu \mathrm{g} \cdot \mathrm{mL}^{-1}\right)$ of VAL and SAC.

\section{Methods validation}

As per ICH guidelines (ICH, 2005), the developed methods were validated for their system suitability, linearity, precision, accuracy, robustness, limit of detection and limit of quantification by applying the following procedures. The method validation parameters are validated and summarized in Table 1.

\section{Range and linearity}

The proposed methods were evaluated and validated in terms of linearity by constructing the calibration graphs within concentration ranges covering the anticipated drug concentration during the assay of the dosage form. Each concentration was analyzed in triplicates.

\section{Detection and quantitation limits}

According to "ICH recommendations", the detection and quantitation limits (LOD, LOQ) of the proposed methods were determined on the basis of calculating the S.D. of the response and the slope. The theoretical values were assessed and listed in Table 1 showing that the low values of LOQ and LOD help to detect and accurately quantify low drug concentrations. 
Table 2: Determination of VAL and SAC in laboratory prepared mixtures and in pharmaceutical formulation by the proposed methods.

\begin{tabular}{|c|c|c|c|c|}
\hline & \multicolumn{2}{|c|}{ HPLC method ${ }^{a}$} & \multicolumn{2}{|c|}{ Densitometric HPTLC method a } \\
\hline & SAC & VAL & SAC & VAL \\
\hline L.P.mixtures $(n=5)^{b}$ & $100.16 \pm 0.89$ & $101.06 \pm 0.26$ & $99.38 \pm 0.86$ & $100.11 \pm 0.45$ \\
\hline Standard addition & $100.76 \pm 0.12$ & $99.98 \pm 0.89$ & $100.55 \pm 0.75$ & $100.36 \pm 0.46$ \\
\hline
\end{tabular}

${ }^{a}$ Mean recovery $\% \pm$ RSD

${ }^{\mathrm{b}}$ average of at least three experiments

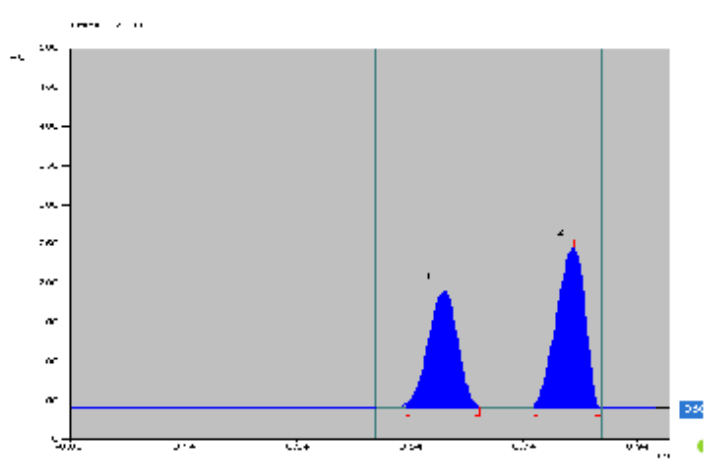

Fig. 3: 2-D TLC-densitometric chromatogram of (a) VAL, (b) SAC (2 $\mu \mathrm{g} / \mathrm{spot}$, each) using ethyl acetate: methanol: glacial acid (9:1:0.1, by volumes) as a mobile phase.at $260 \mathrm{~nm}$.

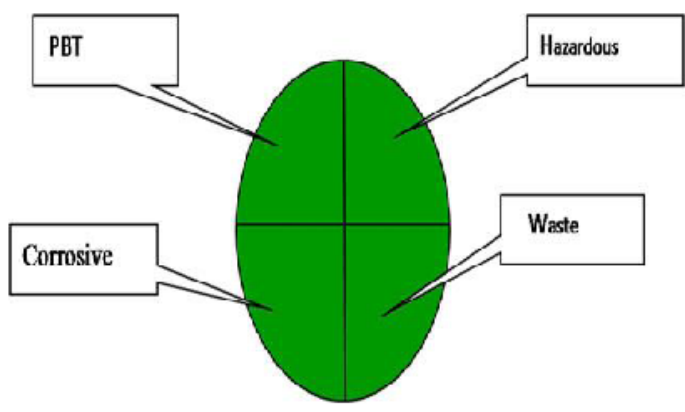

Fig. 4: Greenness profile of the suggested chromatographic methods.

\section{Accuracy}

The accuracy of the proposed methods was ascertained via standard addition technique where different amounts of pure samples of SAC \& VAL; $\left(5,10.20 \mu \mathrm{g} . \mathrm{mL}^{-1}\right.$ for the suggested HPLC method and 1, 1.5, $2.5 \mu \mathrm{g} \cdot \operatorname{spot}^{-1}$ for the HPTLC) were spiked to the previously analyzed tablets. The accuracy expressed as percentage recoveries and presented in Table 2 showed that the pharmaceutical excipients do not exert any interference. The obtained results indicated the good accuracy of the developed methods.

\section{Precision}

"Repeatability" was assessed by analyzing freshly prepared samples in triplicate on the same day with concentrations of 10,20 and $50 \mu \mathrm{g} \cdot \mathrm{mL}^{-1}$ of SAC \& VAL by the proposed HPLC method. While 2, 3 and $4 \mu \mathrm{g} \cdot$ spot $^{-1}$ of SAC \& VAL were selected for the TLC method.

"Intermediate precision" was evaluated in three successive days by assaying solutions of the above-mentioned concentrations in triplicate determinations. Then the recovery $\%$ and RSD\% were calculated (Table 1).

\section{Selectivity}

"Selectivity" was evaluated by analyzing various laboratory prepared mixtures of the drugs under study in different ratios of the linearity range. The obtained RSD values indicated satisfactory percentage recoveries of the lowest standard deviation compared to the other reported methods. The results obtained are mentioned in Table 2. Furthermore, the proposed methods were applied for the determination of SAC and VAL in human plasma and in its dosage form showing no interference from substances from plasma or inactive ingredients in tablet formulation (Figure 2).

\section{Robustness}

"The robustness of the proposed methods" was evaluated by detecting the effect of small, deliberate variations on some of the greatly affecting procedure parameters such as percentage organic strength, flow rate of the mobile phase, travelled distance (8 to 13 $\mathrm{cm}), \mathrm{pH}$, and wavelength. The proposed methods were found to be robust, as all of these varied parameters didn't significantly affect the assay of the cited drugs, Table 1.

\section{Statistical comparison to the reported method}

The results obtained by the suggested procedures were statistically analyzed and compared to the reported HPLC method (Kena et al., 2016). The calculated t- and F-values were found to be less than the theoretical ones, which indicated that there are no significant differences between the proposed methods and the reported one, Table 3 .

\section{System suitability testing (SST)}

Chromatographic parameters and system suitability were validated to assure that the overall system is working properly during the analysis such as resolution, capacity factor $(\mathrm{k})$, tailing factor $(T)$, a relative retention time $(\alpha)$ and number of theoretical plates $(\mathrm{N})$, Table 4. 
Table 3: Statistical analysis of the proposed methods and the official methods of Valsartan (VAL) and Sacubitril (SAC) in their pure form.

\begin{tabular}{lccccc}
\hline & \multicolumn{2}{c}{ HPLC method } & \multicolumn{2}{c}{ Densitometric HPTLC method } & \multicolumn{2}{c}{ Reported method* (Kena et al., 2016) } \\
& SAC & VAL & SAC & VAL & SAC \\
\hline Mean & 100.15 & 100.12 & 99.95 & 100.05 & 100.53 \\
SD & 0.420 & 0.535 & 0.645 & 0.902 & 0.725 \\
N & 8 & 8 & 7 & 9 & 5 \\
Variance & 0.176 & 0.286 & 0.416 & 0.814 & 0.668 \\
Student t-test & $0.913(2.201)$ & $0.619(2.201)$ & $1.203(2.228)$ & $0.395(2.179)$ & 0.526 \\
F & $2.989(4.12)$ & $1.559(4.12)$ & $1.264(4.53)$ & $1.825(6.04)$ & \\
\hline
\end{tabular}

Figures in parenthesis are the corresponding theoretical values at $\mathrm{P}=0.05$.

* HPLC method usin " $\mathrm{C}_{18}(250 * 4.6 \mathrm{~mm}, 5 \mu \mathrm{m})$ column and a mobile phase of acetonitrile: methanol: water $(30: 50: 20, \% \mathrm{v} / \mathrm{v})$ at $267 \mathrm{~nm}$ "

Table 4: Statistical analysis of system suitability testing parameters for the proposed chromatographic methods.

\begin{tabular}{|c|c|c|c|}
\hline \multirow[b]{2}{*}{ Parameters } & \multicolumn{2}{|c|}{ Obtained values } & \multirow[b]{2}{*}{ Reference values (Andrea, 1997; USP 40-NF 35, 2017) } \\
\hline & HPLC & TLC & \\
\hline Resolution (R) & 1.122 & 1.015 & $\mathrm{R}>0.8$ \\
\hline Tailing factor $(\mathbf{T})$ & $\begin{array}{l}\text { SAC: } 1.05 \\
\text { VAL: } 1.20\end{array}$ & $\begin{array}{l}\text { SAC: } 1.00 \\
\text { VAL: } 1.07\end{array}$ & $\begin{array}{c}\mathrm{T}=1 \\
\text { "for a typical symmetrical peak". }\end{array}$ \\
\hline Relative retention ( $\alpha$ ) time (selectivity factor) & 1.338 & 1.482 & $>1$ \\
\hline Capacity factor $(\mathrm{K})$ & 4.437 & 5.026 & $1-10$ are acceptable \\
\hline Column efficiency $(\mathrm{N})$ & 472.98 & & Not Available "increases with the efficiency of separation". \\
\hline HETP & 0.634 & & "The smaller the value, the higher the column efficiency" \\
\hline
\end{tabular}

\section{Greenness profile}

Greenness profiles (Figure 4) have been added to quantify the greenness of the proposed analytical methods. The profile criteria are evaluated via four main quadrants namely; "PBT" (persistent, bio accumulative, and toxic), corrosive, hazardous, and waste. Based on the method fit to these particular criteria, each quadrant could be green or blank (Keith et al., 2007). In the proposed methods; ethanol, ethyl acetate, methanol and water are neither considered as PBT nor hazardous solvents according to the EPA's Toxic Release Inventory. In addition; the amount of waste generated is less than $5 \mathrm{ml}$ per each sample in HPLC method and less than $10 \mathrm{~mL}$ for the TLC method. Therefore, the suggested methods according to these criteria, passed the four quadrants of the greenness profile, and are found to be greener and safer than the reported ones with acceptable validation parameters.

\section{CONCLUSION}

The proposed HPLC and HPTLC methods could be considered green, selective, and sensitive methods for the quantitative simultaneous determination of SAC and VAL, which represent an advantage over the previously published methods. Based on isocratic elution, the proposed d HPLC method provided high selectivity and sensitivity for the determination of SAC and VAL in short analysis time at single wavelength. The proposed HPLC method was found to be more sensitive with lower linearity range and LOD and LOQ values when compared with the reported methods. Moreover, it was successfully applied for determination of both drugs in spiked human plasma with more efficient extraction procedure in addition of being greener one.

The HPTLC-densitometric method has the advantage of improved sensitivity to achieve quantitation limits in the order of nanograms, large sample capacity and short run time, in addition to the use of minimum solvent consumption. A comparative statistical study was developed between the proposed methods and a reported HPLC method using t-test, F-test as presented in Table 3. Data results permit one to conclude that the suggested methods and the reported HPLC method have no. significant statistical difference between them.

Moreover, the suggested green validated methods can replace conventional ones for the analysis of SAC/VAL either in their pure powdered form, in their pharmaceutical formulations, or in plasma samples. The proposed methods neither use nor produce harmful chemicals and successfully pass the four quadrants of the greenness profile. So, the presented methods are considered greener and safer than the reported ones with acceptable validation parameters and therefore they can be applied for routine assay analysis of the cited mixture with no harmful effects on the environment.

\section{COMPLIANCE WITH ETHICAL STANDARDS}

The author declared that the author has" no conflict of interest" and this presented work does not have any studies that have been performed with human participants or animals.

\section{REFERENCES}

Alfonsi K, Colberg J, Dunn PJ, Fevig T, Jennings S, Johnson TA, Peter KH, Knight C, Nagy MA, Perry DA, Stefaniak M. Green chemistry tools to influence a medicinal chemistry and research chemistry based organisation. Green Chem., 2008; 9:31-36.

Andrea W, Phyllis R. HPLC and CE, principles and practice, Academic Press, London 1997.

Armenta S, Garrigues S, De la Guardia M. Green Analytical Chemistry. TrAC Trends Anal. Chem., 2008; 27: 497-511.

Elzanfaly ES, Hegazy MA, Saad SS, Salem MY, Abd El Fattah LE. Validated green high-performance liquid chromatographic methods for 
the determination of co-formulated pharmaceuticals: A comparison with reported conventional methods. J. Sep. Sci., 2015; 38:757-763.

Eric F, Alexander D, Paul R. Development and validation of chiral high-performance liquid chromatographic methods for the quantitation of valsartan and of the tosylate of valine benzyl ester. Journal of Chromatography B: Biomedical Sciences and Applications, 1996; 686 (1):77-83.

US Food and Drug Administration, 2015. FDA approves new drug to treat heart failure. US Department of Health and Human Services, Food and Drug Administration, Available at: http://www.fda.gov/ newsevents/newsroom/press announcements/ucm 453845.htm.

Funari CS, Carneiro RL, Andrade AM, Hilder EF, Cavalheiro A J. Green chromatographic fingerprinting: an environmentally friendly approach for the development of separation methods for fingerprinting complex matrices. J. Sep. Sci., 2014; 37:37-44.

Gandla. KS, Ravindra N., Sowmya S. A new RP-HPLC method development and validation for the simultaneous estimation of amlodipine and valsartan in tablet dosage forms. Asian Journal of Pharmaceutical Analysis, 2014; 4(3):103-107.

Hakan S, Sezgin B and Seyfullah K. Development of an analytical method for the determination of valsartan in commercial drug and sewage sludge samples by HPLC and evaluation of its stability under simulated gastric conditions. Journal of Liquid Chromatography \& Related Technologies, 2016; 39 (11):526-531.

Hao Li, Yingwu Wang, Yao Jiang, Yunbiao Tang, Jiang Wang, Limei Zhao, Jingkai Gu. A liquid chromatography/tandem mass spectrometry method for the simultaneous quantification of valsartan and hydrochlorothiazide in human plasma. Journal of Chromatography B, 2007; 852(1-2):436-442.

ICH Harmonized Tripartite Guideline, Q2(R1) Validation of Analytical Procedures: Text and Methodology, International Conference on Harmonization, Geneva, Switzerland, 2005.

Jothieswari. D, Anandakumar. K, Vijaya Santhi. D, Vijayakumar. B, Priya. D, Stephen Rathinaraj. B. Validated RP-HPLC method for the simultaneous determination of amlodipine besylate, valsartan and hydrochlorothiazide in bulk and pharmaceutical formulation. Journal of Pharmaceutical and Biomedical Sciences, 2010; 5:1-7.

Keith L H, Gron L U, Young J L Green analytical methodologies. Chem. Rev., 2007, 107 (6); 2695-2708.

Kena HP, Shailesh VL, Sachin BN. Simultaneous estimation of sacubitril and valsartan in synthetic mixture by RP-HPLC method. J Pharm Sci Bioscientific Res., 2016; 6(3):262-269.

Koel M, Kaljurand M (2006) Pure Appl. Chem., 78: 1993-2002.

Kobalava Z, Kotovskaya Y, Averkov O, Pavlikova E, Moiseev V, Albrecht D, Chandra P, Ayalasomayajula S, Prescott MF, Pal P, Langenickel TH, Jordaan P, Rajman I. Pharmacodynamic and pharmacokinetic profiles of sacubitril/valsartan (lcz696) in patients with heart failure and reduced ejection fraction. Cardiovasc Ther.,2016;34(4):191-8

Koçyiğit-Kaymakçoğlu B, Unsalan S, Rollas S. Determination and validation of ketoprofen, pantoprazole and valsartan together in human plasma by high performance liquid chromatography. Pharmazie, 2006; 61:586-589

Koseki N, Kawashita H, Hara H, Niina M, Tanaka M, Kawai R, Nagae Y, Masuda N. Development and validation of a method for quantitative determination of valsartan in human plasma by liquid chromatography-tandem mass spectrometry. Journal of Pharmaceutical and Biomedical Analysis, 2007; 43(5):1769-1774.
Lawrence J. Novel heart failure therapy shows 'overwhelming benefit', trial shows. The Pharmaceutical Journal, 2014; 293:7827-7830.

Macek J, Klíma J and Ptáček P. Rapid determination of valsartan in human plasma by protein precipitation and high-performance liquid chromatography. Journal of Chromatography B, 2006; 832 (1):169-172.

Madana GN, Sridhar C. RP-UPLC method for simultaneous estimation of sacubitril and valsartan in its bulk and tablet dosage form with force degradation studies. International Journal of ChemTech Research, 2017; 10 (4):279-287.

McMurray JJ, Packer M, Desai AS, Gong J, Lefkowitz MP, Rizkala AR, Rouleau JL, Shi VC, Solomon SD, Swedberg K, Zile MR and PARADIGM-HF. Investigators and Committees. Angiotensin-neprilysin inhibition versus enalapril in heart failure. The New England Journal of Medicine, 2014; 371:993-1004.

Muqhtar A, Shetty AS, Manzoor A, Vijaya Krishna CA, Anil Kumar SM and Siddalinga Swamy M S. Stability indicating RP-HPLC method for simultaneous estimation of sacubitril and valsartan in bulk and combined pharmaceutical dosage form. World Journal of Pharmacy and Pharmaceutical Sciences, 2017; 6 (4):1714-1728.

Naazneen S, Sridevi A. Development of assay method and forced degradation study of valsartan and sacubitril by RP-HPLC in tablet formulation. International Journal of Applied Pharmaceutics, 2017; 9 (1):915.

Namieśnik J (2001) Green analytical chemistry - Some remarks.J. Sep. Sci., 24:151-153.

Ragab M A A, Galal SM, Korany MA, Ahmed AR. First derivative emission spectrofluorimetric method for the determination of LCZ696, a newly approved FDA supramole cular complex of valsartan and sacubitril in tablets. Luminescence, 2017; 0:1-9.

Raja Haranadha BC, Gowri SD. Development and validation of a reliable and rapid LC-MS/MS method for simultaneous quantification of sacubitril and valsartan in rat plasma and its application to a pharmacokinetic study. Biomed. Chromatogr., 2016; 30:1467-1475.

Siddartha B, Sudheer Babu I, Ch. Ravichandra Gupta, Parthiban C. Analytical method development and validation for simultaneous estimation of nebivolol and valsartan in bulk and pharmaceutical dosage form by RP-HPLC method. International Journal of Pharmacy, 2014; 4(1):340-346

Swathi V, Parthiban P. New method development and validation for the simultaneous estimation of sacubitril and valsartan in a bulk and pharmaceutical dosage forms. International Journal of Research, 2017; 4 (1):17-24.

Thurmann PA. Valsartan: a novel angiotensin type 1 receptor antagonist. Expert Opinion on Pharmacotherapy, 2000; 1:337-350.

United States Pharmacopeia (USP40), National Formulary (NF35). Rockville: The United States Pharmacopeial Convention, Inc. 2017.

How to cite this article:

Abou Al Alamein AM. Validated Eco-Friendly Chromatographic Methods for Simultaneous Determination of Sacubitril and Valsartan in Spiked Human Plasma and in Pharmaceutical Formulation. J App Pharm Sci, 2018; 8(02): 011-017. 